\title{
Spatial articulation affects lightness
}

\author{
TIZIANO AGOSTINI and ALESSANDRA GALMONTE \\ University of Trieste, Trieste, Italy
}

\begin{abstract}
In a recent paper, Agostini and Bruno (1996) showed that the size of simultaneous lightness contrast increases under Gelb lighting. To extend Agostini and Bruno's work, we applied their methodology to a set of more spatially articulated displays. In four experiments, we investigated the role of spatial articulation on the size of the simultaneous lightness contrast effect. In the first experiment, we found a decrease of the simultaneous lightness contrast effect as the spatial articulation increased. In the second experiment (the control experiment), performed under homogeneous illumination, we found that the effect of spatial articulation is not detectable, even though the data seem to show the same trend as that in the previous experiment. In the third experiment, we found that spatial articulation affects not only the middle reflectance region, but also the lowest one. As the spatial articulation increases, the effect on the lightnesses of both regions decreases. In the last experiment, performed with a reduced range of reflectances, we found a lightening effect for all the reflectances and, again, an effect of spatial articulation. The results of these experiments are interpreted according to the model proposed by Gilchrist et al. (in press).
\end{abstract}

A piece of low reflectance paper (black) suspended in midair and illuminated by a beam of light in an otherwise dark room appears to be white (Gelb, 1929). However, if a high reflectance paper (white) is placed next to it, the two surfaces will be perceived roughly according to their reflectances-that is, the first almost black, and the second white.

Recently, Cataliotti and Gilchrist (1995) broke the Gelb effect down into a series of steps. First, the observers were asked to judge a physically black square under Gelb lighting (an illumination border is made to coincide with the outer border of the display, and the rest of the visual field is left in near darkness). In this condition, the physically black square was perceived to be white, as in the classical Gelb experiment. Then the experimenter placed a physically dark gray square next to the first square; the first square was perceived to be light gray, and the second white. Successively, the experimenter introduced a physically middle gray square, a physically light gray square, and a physically white square. As each new higher reflectance square was placed next to the others, it was the newest to be perceived as being white, while the others underwent a darkening effect.

The authors explained these findings as being the result of an anchoring rule stating that the highest luminance

We thank Larry Arend, Paolo Bozzi, Nicola Bruno, Charles de Weert, Alan Gilchrist, and the members of the Accademia degli Incerti of Verona for their valuable suggestions. Special thanks to Robert $O$ 'Shea and to two anonymous referees for their helpful comments that improved and strengthened our paper. Correspondence concerning this article should be addressed to T. Agostini, Dipartimento di Psicologia, Università di Trieste, via dell'Università 7,34123 Trieste, Italy (e-mail: agostini@univ.trieste.it).

-Accepted by previous editor, Myron L. Braunstein in a scene tends to be perceived to be white and constitutes the standard with respect to which the lightness value of the other surfaces is determined (for a review of the anchoring problem, see Cataliotti \& Gilchrist, 1995). The physically black square under Gelb lighting appeared to be white because it was the highest luminance in the visual field. Adding higher reflectance surfaces under the same illumination, as in Cataliotti and Gilchrist's experiments, caused the effect to decrease, because the new highest luminance became the anchor for the other surfaces.

Gilchrist et al. (in press) are working on a general model that explains the lightness perception of surfaces in terms of a compromise among frameworks, which are defined as groups of surfaces that perceptually belong to each other. Each visible framework contributes, to some extent, to the determination of the lightness of every surface in the visual field. According to this model, Cataliotti and Gilchrist's (1995) experiments represented a simplified situation in which the lightnesses of the five squares were the result of a compromise between two frameworks only. These were named by the authors global and local. The global framework consists of the entire visual field, whereas the local framework consists of the experimental display only. Within the global framework, the anchoring rule predicts white for all the surfaces. According to Gilchrist et al., this occurs because all five squares have luminance values that are either roughly equal to or higher than the anchor in the global framework. Therefore, in relation to the global framework, the five surfaces should appear white: it is as if each square undergoes a Gelb effect. Within the local framework, when all the squares are present, the squares span the entire reflectances range, and therefore, one would expect veridical lightness perception (i.e., no difference between the objective and the perceived Munsell value). Cataliotti and Gilchrist obtained results that were halfway between 
the prediction based on the global framework and that based on the local framework. These results suggest that the lightness of each surface was determined by a compromise between these two frameworks (see Figure 1).

Recently, Agostini and Bruno (1996) studied the classical simultaneous lightness contrast display (see Figure 2) under Gelb lighting. From a Munsell scale arranged on a white background, the observers had to choose the shade of gray that matched the lightness of a gray target placed on a black background. The scale and the experimental display were both under Gelb lighting. In these stimulation conditions, the simultaneous lightness contrast effect is almost two Munsell units larger than that under a homogeneous illumination condition (the whole experimental room illuminated by an approximately homogeneous illumination). Starting from the Gelb condition and progressively including more of the context within the same area of higher mean luminance, the size of the simultaneous lightness contrast decreased. From this set of results, the authors concluded that a major factor affecting the simultaneous lightness contrast effect in paper-and-illuminant displays is the spatial distribution of illumination.

It is important to note that the experimental displays in the earlier experiments were always very simple. In the present work, we used more complex displays-for example, the Benary configuration-in which it is necessary to emphasize the idea of perceptual belongingness to account for the effect (Agostini \& Proffitt, 1993; Benary, 1924; Kanizsa, 1975; Koffka, 1935; Wertheimer, 1923). For this reason, we introduce a general princi- ple-that is, that of perceptual spatial articulation. We use the term perceptual spatial articulation to refer to the result of a perceptual organization process selecting and highlighting specific physical spatial relationships of a visual pattern. Perceptual belongingness, however, refers to the result of a connection process unifying the specific perceptual attributes arising from spatial articulation.

Consider the following example. A number of identical small disks are equidistantly spaced along the perimeter of a circle. Perceptual organization processes acting on the physical attributes of this pattern will give rise to the perception of a circle of small disks. The circle arises from perceptual spatial articulation. Each individual disk appears to belong to the circle. It is in this way that perceptual spatial articulation determines the specific belongingness relationships among the elements. We propose that perceptual spatial articulation also determines the perception of the surface colors of areas in the visual field. Perceptual spatial articulation is an operational concept, helping to formulate predictions about the lightness value taken by a particular region of the visual field. We assume that spatial articulation is low when there are few different reflectances and simple spatial relationships and that it becomes greater when there are more areas of different reflectance and/or their spatial relationships are more complex. Low spatial articulation determines univocal belongingness relationships, whereas high spatial articulation produces manifold belongingness relationships. Therefore, the lightness of a region is the result of the influence of one or more belongingness relationships.
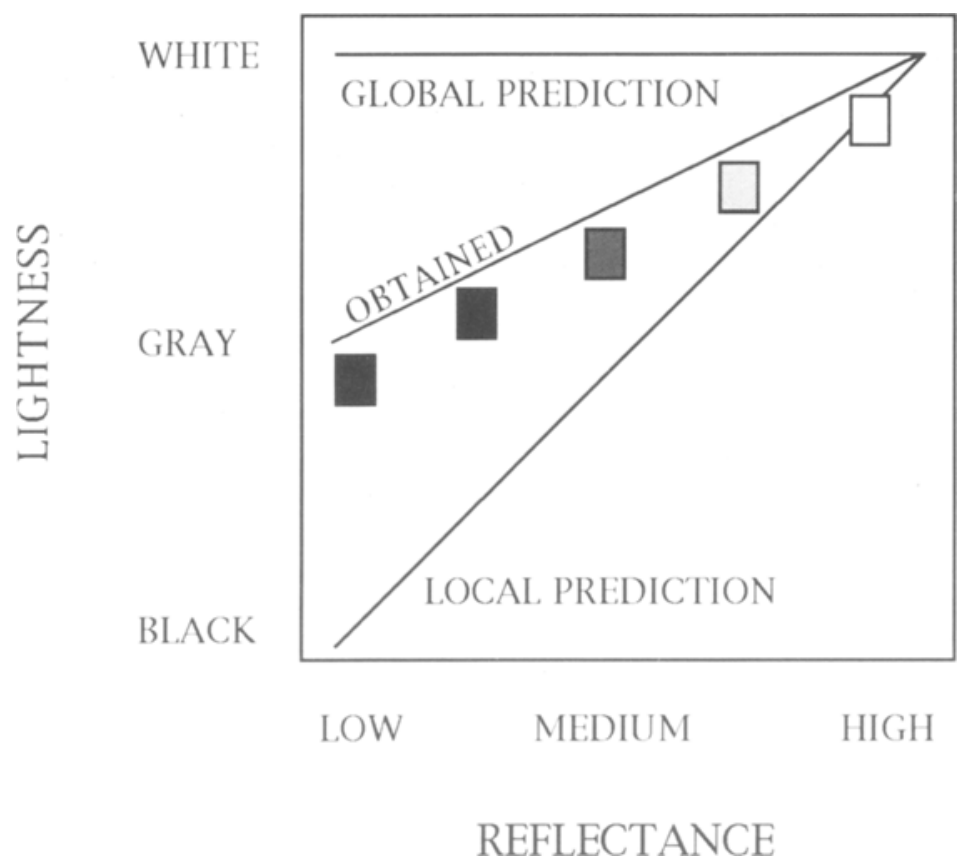

Figure 1. Predictions of lightness perception according to Gilchrist et al.'s (in press) model. 


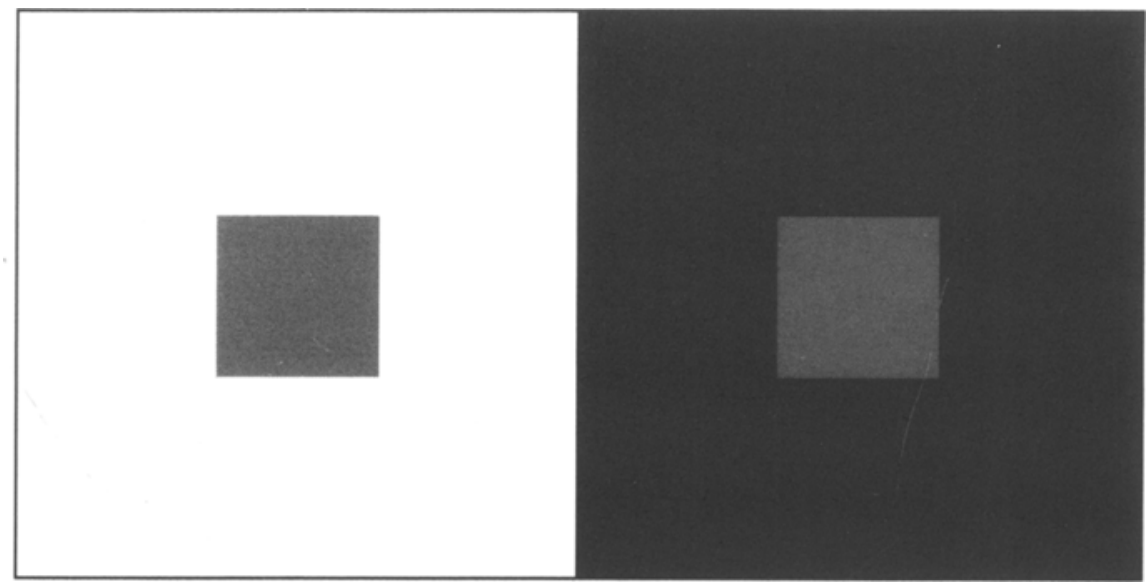

Figure 2. Classic simultaneous lightness contrast display. The gray square on the white background appears to be darker than that on the black.

To extend Agostini and Bruno's (1996) work, we applied their methodology to a set of more spatially articulated displays. We predict that an increase of spatial articulation should produce an increase of the strength of the local framework. Since the local framework predicts veridical lightness perception, an increase of its strength should reduce the contrast effect observed by Agostini and Bruno under Gelb lighting.

\section{EXPERIMENT 1}

In the first experiment, the effect of spatial articulation on lightness contrast phenomena was tested. In several displays that can all be considered to involve contrast, we manipulated reflectances and spatial relationships (inclusions and adjacencies) in order to produce different levels of spatial articulation (see Figure 3 ). We assumed that, ceteris paribus, the number of different reflectances, the number of inclusions, and the number of adjacencies were, in that order, the most important factors in determining the degree of spatial articulation in our displays. In our displays we had: display a, one inclusion, two surfaces having different reflectances; display $b$, one inclusion, one adjacency, three surfaces having different reflectances; display c, one inclusion, two adjacencies, three surfaces having different reflectances; display d, two in-

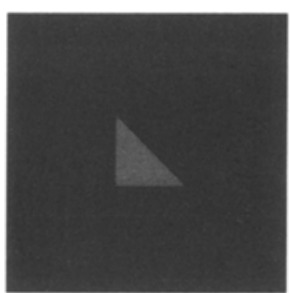

a

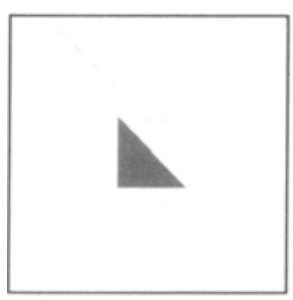

$a^{\prime}$

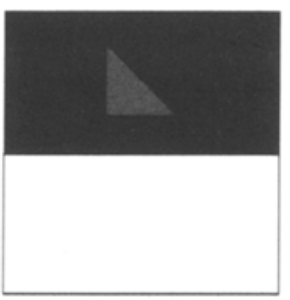

b

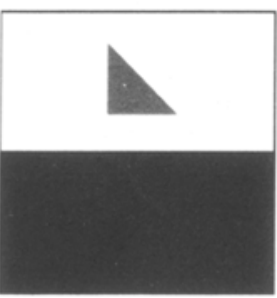

$b^{\prime}$
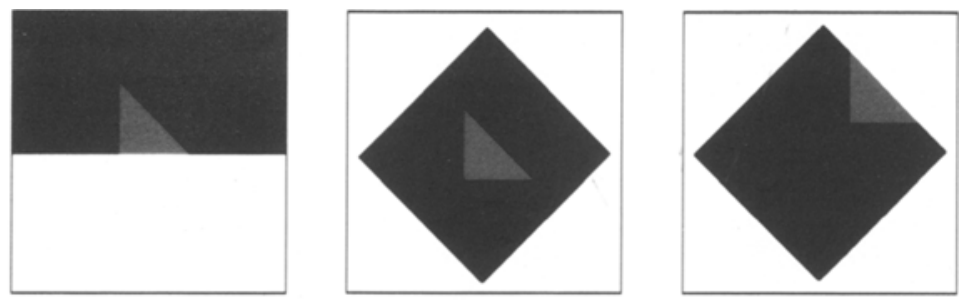

C
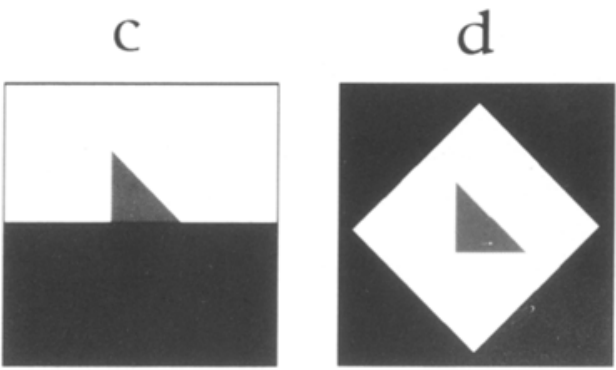

e

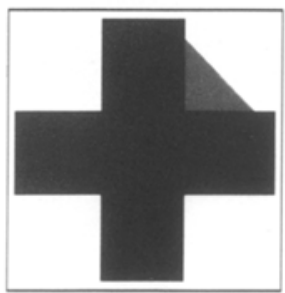

$\mathrm{C}^{\mathbf{1}}$
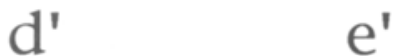

Figure 3. Experimental displays. 


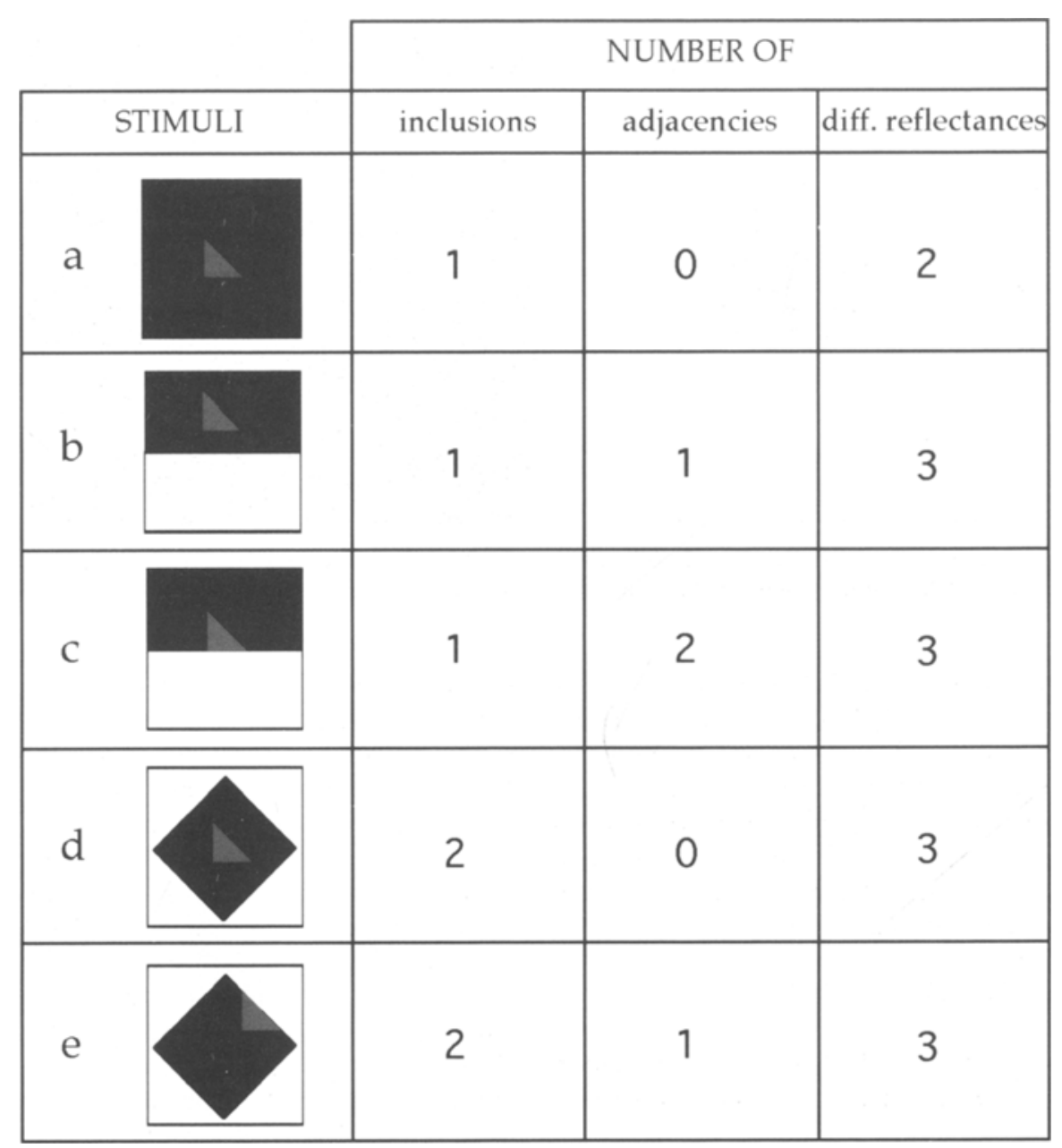

Figure 4. The factors determining the degree of spatial articulation.

clusions, three surfaces having different reflectances; display e, two inclusions, one adjacency, three surfaces having different reflectances (see Figure 4). It must be noted that the factors that we offered could be used only to order our experimental displays on the basis of spatial articulation. In order to make quantitative predictions, further experiments would be necessary, to define the weight and the role of the factors. Among the displays, we included also the Benary configuration. We used the method of Gelb lighting, since Agostini and Bruno (1996) had shown that it increased the size of the classic simultaneous lightness contrast effect. In this paper, the effect is considered to be defined by the difference between the objective and the perceived Munsell value of a surface.

\section{Method}

Observers. One hundred and twenty volunteer observers participated in this experiment ( 12 per condition). They were all undergraduate or graduate students at the University of Trieste, who were naive as to the purpose of the study.
Apparatus and Stimuli. All 10 conditions were tested under Gelb lighting. Figure 3 depicts the 5 experimental conditions $(a-e)$ and the 5 control conditions $\left(a^{\prime}-e^{\prime}\right)$. The displays were squares $(33 \times 33 \mathrm{~cm})$, and, except for the displays a and $\mathrm{a}^{\prime}$ (the two displays of classic contrast), the amount of black and white area was the same in all the displays. The displays $\mathrm{e}$ and $\mathrm{e}^{\prime}$ can be considered to be equivalent to the classic Benary configuration. The target was a middle gray right triangle of constant area and spatial orientation (short sides, $5.5 \mathrm{~cm}$ ). The white area had the highest luminance and reflectance (luminance, 75 nit; Munsell value, 9.5/), the middle gray intermediate (5.5/), and the black the lowest (2.0/). A Munsell scale on a white background $(33 \times 33 \mathrm{~cm})$ was placed next to the experimental display. The scale consisted of 16 small rectangles $(4 \times 1 \mathrm{~cm})$ ranging from black $(2.0 /)$ to white $(9.5 /)$. Both the Munsell scale and the experimental display were hung on a wall of the laboratory and were viewed from a distance of $2 \mathrm{~m}$. A rectangular beam of light was projected by a halogen lamp that was hidden from the observer, so that the illumination border coincided with the external border of the two displays; this kind of illumination is referred to as Gelb lighting. The experimental room was dimly illuminated by indirect light from the same lamp.

Procedure. The observers waited in a normally illuminated area. They were taken into the experimental room and placed in front of 
the experimental display. After they had seen the display, the experimenter read the following instructions while pointing to the corresponding surfaces: "In front of you, in the middle of one of the two displays, there is a triangle, while on the near display, there are 16 gray rectangles ranging from black to white. Your task is to identify the rectangle that has been cut from the same paper as the triangle." The observers responded by pointing to one of the rectangles and then left the room. Each observer performed one match in one condition only.

\section{Predictions}

Our principle of spatial articulation predicts the relative size of contrast effect for each of the displays we selected. For display a of Figure 3, we expected the maximum simultaneous lightness contrast effect, since it had lower spatial articulation, whereas for display e, we expected the minimum effect, since it had higher spatial articulation. For the other displays, we predicted a decrease of contrast effect from display a to display e, corresponding to their increase in spatial articulation. All the displays with the gray triangle on the white region served as control matches, because the Munsell scale was always on a white background and, therefore, we expected veridical matches.

\section{Results and Discussion}

For three of the control displays $\left(a^{\prime}, b^{\prime}\right.$, and $\left.d^{\prime}\right)$, the mean value of the lightness matches was not statistically different from the objective value (5.5/). This result was expected, because the matching Munsell scale was on a white background. The mean lightness values of the control displays $\mathrm{c}^{\prime}$ and $\mathrm{e}^{\prime}$, however, were slightly but significantly higher $(6.0 /)$ than the objective values [one-group $t$ test: display $\mathrm{c}^{\prime}, t(11)=2.22, p<.05$; display $\mathrm{e}^{\prime}, t(11)=$ $4.07, p<.005]$.

In the experimental displays ( $a, b, c, d$, and $\mathrm{e}$ ), in which the target was placed on a black area, the increase of contrast was maximum for display a and minimum for display e (see Figure 5). Figure 5 also shows the comparisons between the mean matches that were significant in unpaired $t$ tests for independent samples. The increase in contrast seemed to depend on spatial relationships among areas in the configuration. In display a, the size of the contrast effect was the largest; in displays $b$ and $c$, it was intermediate (the black area was adjacent to a white area); and in displays $d$ and e, the contrast was the lowest (the black area was included in a white area). We also observed an effect of gray target position (either in the

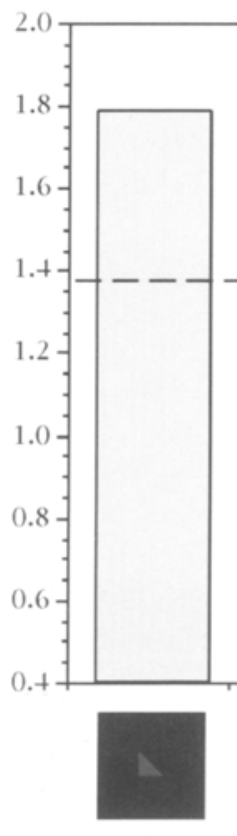

a

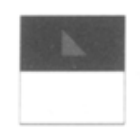

b
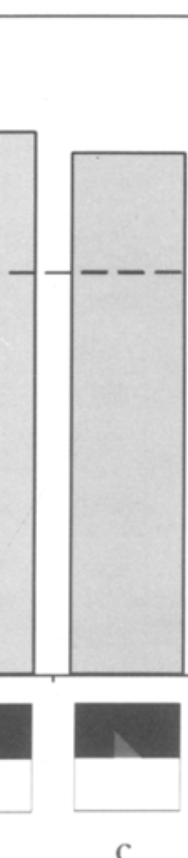

C
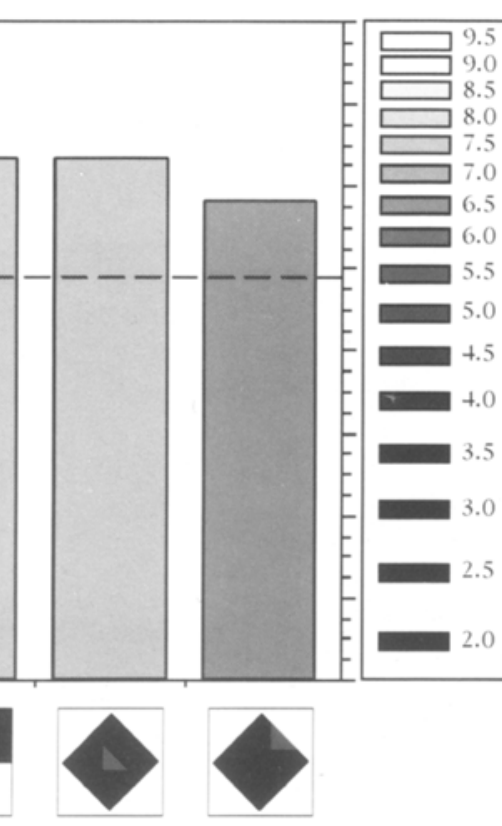

d

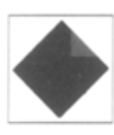

e

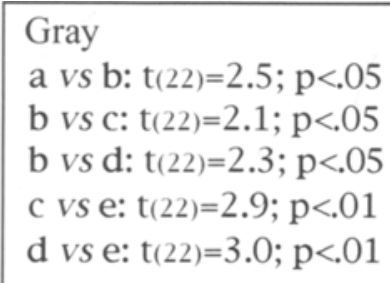

--- Objective value

Figure 5. The results of Experiment 1. 
middle of the black region, as in displays $a, b$, and $d$, or on the border between two regions, as in displays $\mathrm{c}$ and $\mathrm{e}$ ). Within the same configuration, the size of the contrast effect varied as the target position changed: It was bigger when the target was in the middle of a region and smaller when the target was on the border between two regions.

Surprisingly, we did not find any statistical difference between the mean of lightness matches obtained for display e and that obtained for display $\mathrm{e}^{\prime}$ (the classical Benary configuration).

\section{EXPERIMENT 2 Control Experiment}

All the conditions of Experiment 1 were performed under Gelb lighting. We performed a second experiment, to test whether it is also possible to detect the effects of spatial articulation on lightness under homogeneous illumination.

\section{Method}

Observers. Forty-eight volunteer observers participated in this experiment ( 12 per condition). They were all undergraduate or graduate students at the University of Trieste, naive as to the purpose of the study. None of them had participated in Experiment 1.

Apparatus and Stimuli. All the conditions (four) were tested under homogeneous illumination. There were three experimental displays $(a, b$, and $e)$ and one control display $\left(a^{\prime}\right)$, chosen from those used in Experiment 1. We selected these because they showed, respectively, the maximum, medium, and minimum contrast effects. The only difference between this experiment and the previous one was the environmental lighting that, here, was constituted by the homogeneous illumination produced by the diffuse artificial light of the laboratory.

Procedure. The procedure was the same as that in Experiment 1.

\section{Predictions}

Since Agostini and Bruno (1996), in their experiments, had found an increase of contrast only under Gelb lighting, we expected that, under homogeneous illumination, the effect that was due to spatial articulation, measured in Experiment 1, would be minimal or not detectable at all.

\section{Results and Discussion}

For display a', in which the target was placed on a white region, the mean of the matches made by the observers was, again, not statistically different from the objective Munsell value. In this illumination condition (see Figure 6), the differences among the mean values for the other displays ( $a, b$, and e) were smaller than those in Experiment 1 . They were not statistically different in a factorial analysis of variance (ANOVA). Thus, under Gelb lighting, it was possible to observe effects of spatial articulation on the size of the contrast effect, whereas under homogeneous illumination, this was not possible.

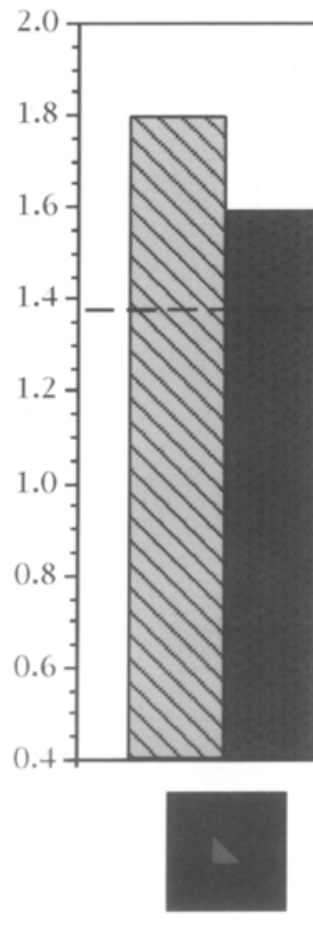

a
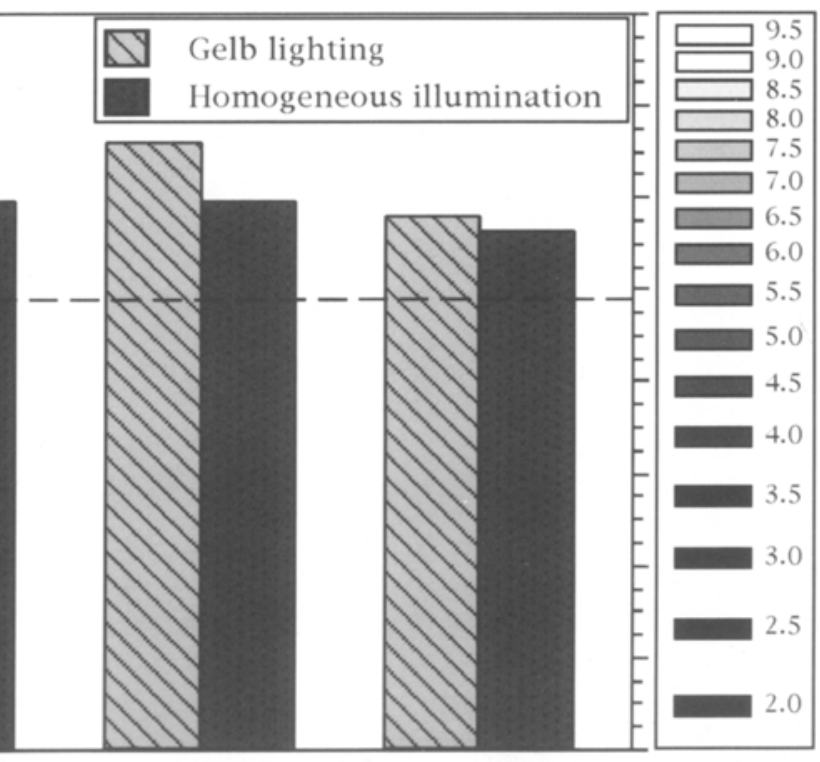

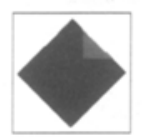

e

- - - Objective value

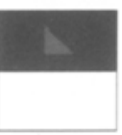

b

Figure 6. The results of Experiment 2. 


\section{EXPERIMENT 3}

Agostini and Bruno (1996) found that the size of simultaneous lightness contrast effect approximately doubles under Gelb lighting. However, Cataliotti and Gilchrist (1995) found that, when the whole range of reflectances (from black to white) was present, the lightnesses of all the regions, except for the white, scaled in the direction of compression; for example, the lowest reflectance was perceived to be dark gray rather than black. This effect might account for Agostini and Bruno's results. We performed a third experiment, to test whether spatial articulation, measured under Gelb lighting, produces an increase of simultaneous lightness contrast or, instead, affects the lightnesses of all the surfaces in the visual field.

\section{Method}

Observers. Eighty-four volunteer observers participated in this experiment ( 12 per condition). They were all undergraduate or graduate students at the University of Trieste, who were naive as to the purpose of the study. None of them had participated in the previous experiments.

Apparatus and Stimuli. The seven displays used in this experiment were selected from those used in Experiment 1 (see Figure 3). In this experiment, we eliminated all the control displays, except for ' $c^{\prime}$ and $e^{\prime}$, which, in Experiment 1, had led to mean values higher than the objective one. Size, luminances, and Munsell values were the same as those in Experiment 1. The apparatus was similar to that used in the previous experiments, except for the relative position of the experimental display and the matching Munsell scale. In this case, both were suspended in midair $1 \mathrm{~m}$ away from the wall of the lab and were $58 \mathrm{~cm}$ from each other (from center to center). All the displays were seen under Gelb lighting.

Procedure. The procedure was the same as that in Experiment $\mathbf{l}$, except that now observers were asked to make a lightness match for each region of different reflectance present in the experimental display. The request order was pseudorandom.

\section{Predictions}

Our principle of spatial articulation predicted the maximum increase of lightness induction ${ }^{2}$ for both the gray triangle and the black background of display a, because it had lower spatial articulation, and the minimum increase for display e, because it had higher spatial articulation. For the other displays we predicted a decrease of the induction effect from display a to display e, corresponding to the increase of spatial articulation.

\section{Results and Discussion}

The induction effect on the gray regions was maximum in display a and minimum in display e. The same trend was observed for the black regions, which were always

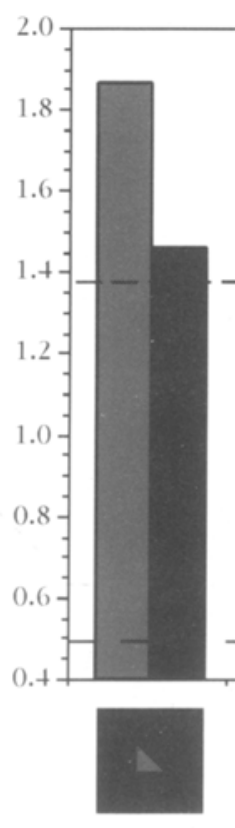

a

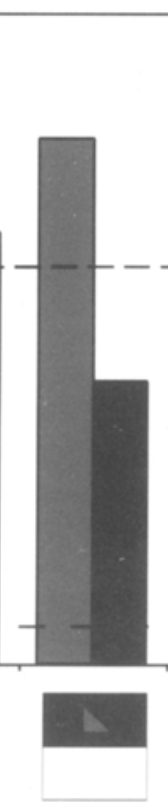

b
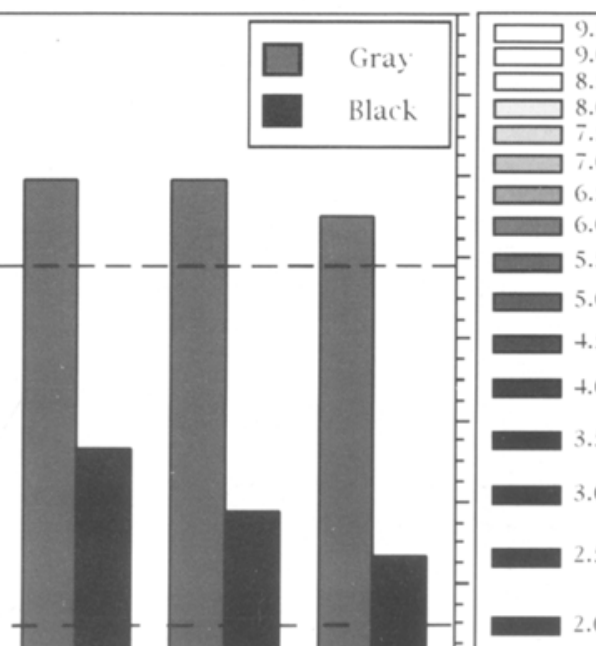

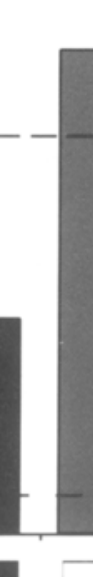

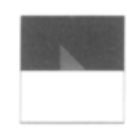

C

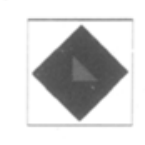

d

\section{Gray}

a vs b: $\mathrm{t}(22)=6.3 ; \mathrm{p}<.001$

b vs $\mathrm{c}: \mathrm{t}(22)=3.2 ; \mathrm{p}<.01$

b vs $\mathrm{d}: \mathrm{t}(22)=2.7 ; \mathrm{p}<.05$

c vs e: $\mathrm{t}(22)=2.3 ; \mathrm{p}<.05$

$\mathrm{d} v s$ e: $\mathrm{t}(22)=2.2 ; \mathrm{p}<.05$

Black

a $v s$ b: $\mathrm{t}(22)=3.8 ; \mathrm{p}<.001$

b vs d: $\mathrm{t}(22)=3.07 ; \mathrm{p}<.01$

c vs d: $\mathrm{t}(22)=2.07 ; \mathrm{p}<.05$

Figure 7. The results of Experiment 3. 
lighter than their objective value (see Figure 7). The white regions were judged correctly and, therefore, are not graphed. Figure 7 shows also the comparisons between the mean matches that were statistically significant in unpaired $t$ tests for independent samples.

However, the lightening of the black region is greater than that of the gray region. This implies a perceptual compression. That is, the difference between the perceived lightness of the gray region and the perceived lightness of the black region is reduced as spatial articulation decreases. A factorial ANOVA, conducted on the differences between the logs of the perceived reflectances of the gray regions and those of the black regions among conditions b, c, d, and e, was significant $[F(3,44)=3.364$; $p<.05] .{ }^{3}$ Condition a was not included in the analysis, since there was not a veridical white. Thus, under Gelb lighting, it is possible to observe how spatial articulation affects the lightness of both the gray and the black regions.

Again, we found effects of spatial relationships on lightness. Spatial relationships seem to be crucial for explaining the lightness values taken by the gray and the black areas. Both the gray and the black areas were pushed toward white when there was no objective white in the display (see display a: black, 5.92/; gray, 8.75/), and both stayed close to their objective values when the black area was surrounded by an objective white region (see displays d: black, 2.87/; gray, 6.75/; and e: black, 2.5/; gray, $6.16 /$ ). When a white region was placed next to the black area but did not surround it, the gray and the black areas were also pushed toward white, but to a lesser extent (see displays b: black, 4.04/; gray, 7.42; and c: black, 3.42/; gray, $6.71 /$ ).

In displays $\mathrm{c}^{\prime}$ and $\mathrm{e}^{\prime}$, the lightness mean value was again slightly but significantly higher $(6.0 /)$ than the objective value [one-group $t$ test: display $\mathrm{c}^{\prime}, t(11)=3.53$, $p<.005$; display $\left.\mathrm{e}^{\prime}: t(11)=3.84, p<.005\right]$.

Again, the average matches for displays e and $\mathrm{e}^{\prime}$ (the classical Benary configuration) were not statistically different.

No effect of the request order was found.

If we assign the arbitrary value of 1.5 to each reflectance, 1 to each inclusion, and 0.5 to each adjacency and add up these values according to the number of factors in each display, we can correlate the degree of spatial articulation with the observed lightness matches. For example, in display a there were two different reflectances (arbitrary value, 3 ) and one inclusion (arbitrary value, 1), so that the total degree of spatial articulation was 4 . Given this way to weight the factors, we found significant regression for both the gray $(r=.96)$ and the black $(r=.95)$ regions of our displays.

\section{EXPERIMENT 4}

The purpose of this experiment was to test whether spatial articulation under Gelb lighting produces a lightening effect on all the regions of the experimental displays. In Experiment 3, the mean values given by the ob-

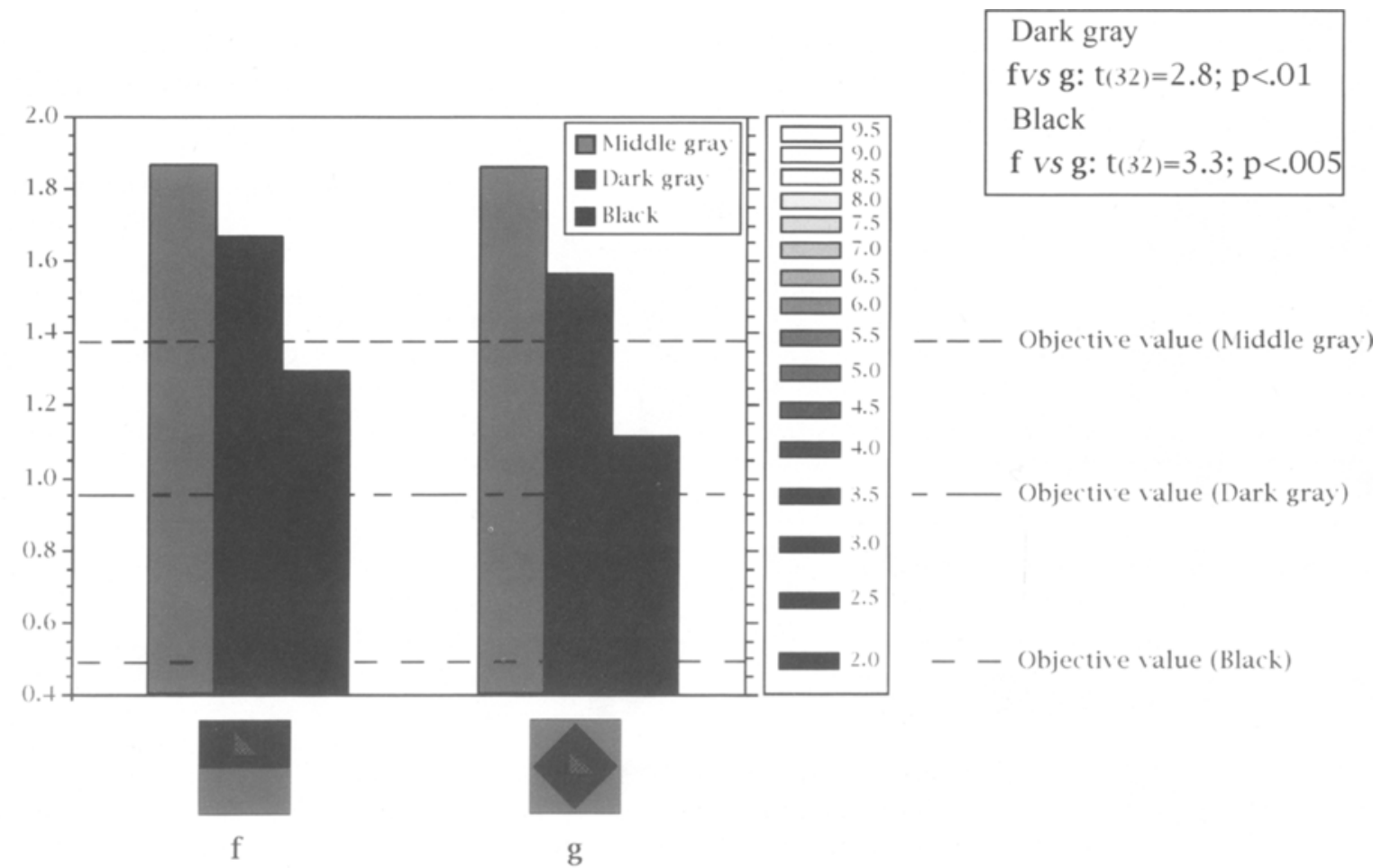

Figure 8. The results of Experiment 4. 
servers to the white region were not statistically different from the objective values. From that experiment, it is not possible to establish whether the lightness of the white region did not change when put under Gelb lighting or whether the change was not detectable because of a ceiling effect. In this experiment, we reduced the range of reflectances, using displays having black, dark gray, and middle gray regions.

\section{Method}

Observers. Thirty-four volunteer observers partıcipated in this experiment ( 17 per condition). They were all undergraduate or graduate students at the University of Trieste, who were naive as to the purpose of the study. None of them had participated in the previous experiments.

Apparatus and Stimuli. We selected displays b and d from those used in the previous experiments. The spatial configurations of the displays were the same, but reflectances and luminances were different (see Figure 8). We called these displays $f$ and $g$. The apparatus was the same as that in Experiment 3. All the displays were seen under Gelb lighting.

Procedure. The procedure was the same as that in Experiment 3. The request order was pseudorandom.

\section{Predictions}

In this condition, we predicted that ail the tested regions would appear lighter, with a larger increase for the display having lower spatial articulation.

\section{Results and Discussion}

All the tested regions underwent a lightening effect (see Figure 8). In particular, the region with higher reflectance (middle gray) appeared to be almost white. It did not reach the upper end of the Munsell scale, probably because there was, in the scene, an objective white - that is, the background of the scale. The comparisons between the mean values were statistically significant in unpaired $t$ tests for independent samples. Between the two displays, there was a significant difference for the black and the dark gray regions, but not for the middle gray. These results suggest that spatial articulation also affects the lightness of the tested regions when there is not a veridical white in the visual field. It is interesting to note that an unpaired $t$ test for independent samples, conducted on the differences between the logs of the perceived reflectances of the dark gray regions and those of the black regions between conditions $f$ and $g$, was not significant. This means that the perceived differences between the dark gray and the black regions of these two displays was constant-that is, they were scaled by the same amount.

No effect of the request order was found.

\section{GENERAL DISCUSSION}

The results of this extension of Agostini and Bruno's (1996) work show that, under Gelb lighting, the lightness induction effect in simultaneous contrast displays is a function of spatial articulation. The increase of the lightness values was maximum in display a (standard si- multaneous lightness contrast display), in which the spatial articulation was lower, and minimum in display e (Benary configuration), in which the spatial articulation was higher. The lightnesses of both the middle and the lower reflectance areas were affected by spatial articulation, whereas the higher reflectance regions were perceived to be white or almost white.

Our results can be interpreted according to the idea of compromise among frameworks, the relative strengths of which change as a function of spatial articulation. The latter determines the belongingness among the surfaces in the visual field.

Following the interpretation of Gilchrist et al. (in press), all the regions in the experimental displays had higher luminance values within the global framework. As we said in the introduction, this would produce a Gelb effect for each region. In terms of the local framework, which consists of the scale and the experimental display, the lightnesses of all the surfaces in the scene should be veridical, because the full range of lightness values was always present. Since the influence of the scale can be considered to be constant, our results are determined by the variation of the strength of the local framework in relation to the global one, as a function of the variation of spatial articulation within the experimental display.

The changes of spatial articulation produced changes in the belongingness of the tested regions within the experimental displays. These changes of spatial articulation determined the weight of the local framework on the resulting lightness values.

The result was a compromise between the predictions made by the local and the global frameworks, and this result changed as a function of the relative strength of the two frameworks - that is, in this case, as a function of spatial articulation.

The results of Experiment 3 are plotted in Figure 9, in comparison with the predictions of the global and the local frameworks. Note that only two points are plotted for display a. This is because, in this experimental display, there was no real white. Figure 9 also shows a scaling effect in the direction of compression, the result of the compromise between the local and the global frameworks as a function of spatial articulation, which changed the relative strength of both frameworks.

Summarizing the results of Experiments 1 and 3, the induction effect was maximum when the spatial articulation was lower, it decreased when there was spatial adjacency with a real white, and it further decreased with increased spatial articulation (inclusion in a white area).

Changing the position of the gray triangle from the center of the black area to the border with the white (display b vs. display c; display d vs. display e) decreased the lightness induction effect for both the black and the gray areas, because this change produced an increase in spatial articulation. Moving the gray triangle from the center of the black area to the border with the white produced a change in the spatial relationships among all the 


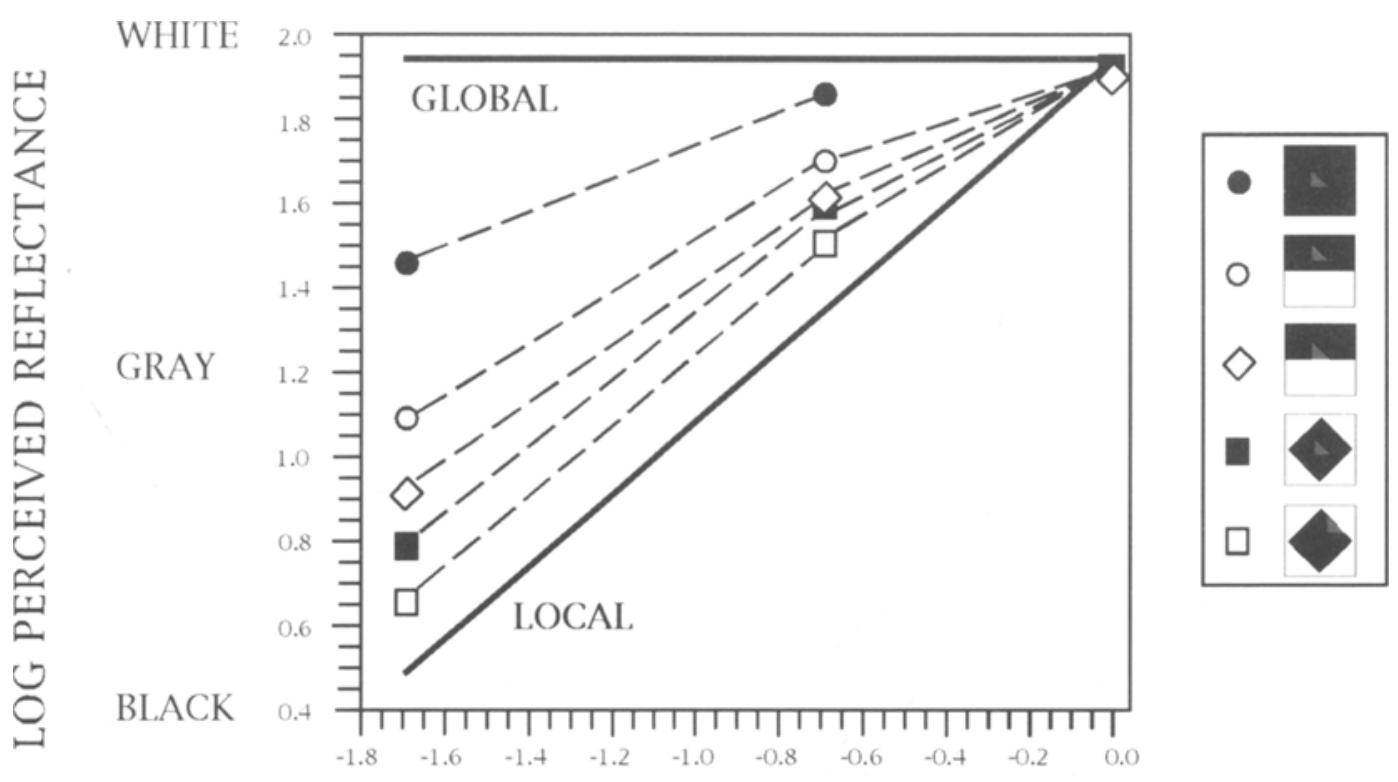

LOG L/Lmax

Figure 9. Comparison between the predictions made by the global and the local frameworks and the empirical data obtained in Experiment 3.

reflectances. When the gray surface was surrounded by a black area (displays $b$ and d), the gray was spatially related only to the black, whereas when the gray also bordered on the white (displays $c$ and e), it was spatially related to both the black and the white areas. The black area was scaled in relationship to the lightness value taken by the gray.

By similar reasoning, it is also possible to interpret the results of Experiments 1 and 3, in which the gray areas of displays $c^{\prime}$ and $e^{\prime}$ were perceived to be lighter than the objective values. These conditions are similar to those we just described. Following the same reasoning as that for displays $c$ and $e$, it was possible to predict that outcome. This idea also can explain why we did not find a significant difference between the gray regions in the Benary configuration (displays e and $\mathrm{e}^{\prime}$ ).

The results of Experiment 4 show that spatial articulation affected the lightness of the tested regions even when there was not a veridical white in the visual field. With the reduced reflectance range, the middle gray was perceived to be almost white, whereas the lightnesses of the black and the dark gray regions were enhanced roughly by the same amount. In this experiment, some observers spontaneously reported an impression of double illumination when presented with display f, although they reported having no problem in the performance of the task. The half of the display having lower reflectance was perceived as a black region highly illuminated, whereas the other half of the display, having middle reflectance, was perceived as a white region dimly illuminated or in shadow. This phenomenon had been previously observed
(Bühler, 1922; Hering, 1920, 1964; Kaila, 1923; Kardos, 1934; MacLeod, 1947; Musatti, 1953; Terstenjak, 1950) and has been called scission (spaltung).

Finally, it must be noted that, in another experiment of the quoted work, Agostini and Bruno (1996) simulated the paper-and-illuminant displays on a cathode-ray tube (CRT) monitor. They found a lightness induction effect similar to that observed under Gelb lighting. As we saw above, they were able to reduce significantly the size of the induction effect in paper-and-illuminant displays by changing the illumination conditions from Gelb to a wider area. In CRT displays, on the other hand, they were not able to find conditions with a normal size lightness induction effect. They obtained only a small decrease of the effect, by surrounding the simulated display with either a Mondrian pattern or a homogeneous middle gray background. Supposing that paper-and-illuminant displays under Gelb lighting act as CRT-simulated displays, our results suggest that a better way to reduce the size of the lightness induction effect on a CRT monitor would be to surround the test pattern by a white region.

\section{REFERENCES}

Aciostini, T., \& BRUNo, N (1996). Lightness contrast in CRT and paperand-illuminant displays. Perception \& Psvchophvicics, 58, 250-258. Agostini, T., \& Proffitt, D. R. (1993). Perceptual organization evokes simultaneous lightness contrast Perception, 22, 263-272.

BF NARY, W. (1924). Beobachtungen zu einem Experıment über Hellıkeitskontrast [Observation on a brightness contrast experiment] $P s v$ chologische Forschung, 5, 131-142.

Bi HLER, K (1922). Handbuch der psvchologit [Handbook of psychology]. Jena. Fischer 
Catal.jotti, J., \& Gilchrist, A [L.] (1995). Local and global processes in surface lightness perception. Perception \& Psychophysics, 57, 125-135.

Gel B, A. (1929). Die "Farbenkonstanz" der Sehdınge [Object color constancy]. In W A. von Bethe (Ed.), Handhuch der normalen und pathologischen Physiologie (pp. 594-678). Berlın: Sprınger-Verlag.

Gilchrist, A. L, Kossyfidis, C, Bonato, F., Agostini, T., CataLiotTI, J., LI, X., SPehar, B., \& Szura, J. (in press). A new theory of lightness perception. Psvchological Review.

HERING, E. (1964). Outlines of a theorv of light sense Cambridge, MA. Harvard L'niversity Press. (Original work publıshed 1920)

Kall. A. E. (1923). Gegenstandsfarbe und Beleuchtung [Object color and illumination]. Psvchologische Forschung, 3, 18-ss.

KanizSA, G. (1975). La percezıone [Perception]. In G Kanızsa, P. L.egrenzi, \& P. Meazzını (Eds.), I processi cognitivi (pp. 13-209). Bologna. II Mulıno

Kardos, L. (1934). Ding und Schatten [Thıng and shadow]. Leıpzig: Barth.

KoffKA, K. (1935). Principles of Gestalt psvchology New York Harcourt, Brace \& World

MacLEOD, R B (1947). The effects of "artificial penumbrae" on the brightness of induced areas. In Miscellanea psvchologica Albert Michotte (pp. 138-156) Paris: Publisher

MusatTI, C. (1953). Luce e colore ne fenomenı del contrasto simultaneo, della costanza e dell'eguaglıamento [Experımental research on chromatic perception: L.ıght and color constancy, contrast, and ıllumination phenomena]. Archivio di Psicologia, Neurologia e Psichiaria, 5, 544-577.

Terstenjak. A. (1950). Farbenkonstanz und Farbenkontrast im L.ıchte der Sonderung und Verschmelzung optischer Eindrücke [Color constancy and color contrast viewed as the separation and fusion of optic sensatıons]. In Contributi del Laboratorio di psicologia dell 'Lniversità Cattolica del Sacro Cuore Serie XIV (pp. 109-147).

WERTHEJMER, M. (1923). Untersuchungen zur Lehre von der Gestalt. Psychologische Forschung, 4, 301-350 [translated as "Laws of organization in perceptual forms" in W D. Ellis (Ed.), A source book of Gestalt psychology (1939, London: Routledge \& Kegan Paul)].

\section{NOTES}

I Even though the presence of the scale and the experimental display within the same illumination unavoidably affects the perception of the surfaces present in the visual scene, we chose this solution in order to avold a Type I error (see Agostını \& Bruno, 1996). Since the scale is present in all the experimental conditions, its influence can be considered to be constant. Furthermore, this solution allowed the observers to make a simultaneous match between the lightness of the target region and that of the patches on the scale.

2. By induction effect, we mean the increase of lightness determined by the scalıng in relationship to the anchor.

3. It must be noted that Fisher's post hoc comparisons were not signıficant for displays b, c and d, e. This means that the perceived differences between the gray and the black regions for these pairs of displays were constant--that is, they did not change their relative position, but rather their absolute position, on the lightness continuum.

(Manuscript recelved August 1, 1996; revision accepted for publication June 14, 1998.) 